\title{
Measuring Light Air Ions in a Speleotherapeutic Cave
}

\author{
Z. Roubal ${ }^{1}$, K. Bartušek ${ }^{2}$, Z. Szabó ${ }^{1}$, P. Drexler ${ }^{1}$, J. Überhuberová ${ }^{3}$ \\ ${ }^{1}$ Department of Theoretical and Experimental Engineering, Faculty of Electrical Engineering and Communication, Brno \\ University of Technology, Technická, 3082/12,61600,Brno, Czech Republic, roubalz@feec.vutbr.cz, szaboz@feec.vutbr.cz, \\ drexler@feec.vutbr.cz \\ ${ }^{2}$ Institute of Scientific Instruments, Academy of Sciences of the Czech Republic, Kralovopolska, 147, 61200, Brno, Czech \\ Republic, bar@isibrno.cz \\ ${ }^{3}$ Children's Speleotherapy Medical Centre, South Moravian Children's Medical Facilities (public benefit organisation), \\ Ostrov u Macochy, 389, 67914, Ostrov u Macochy, Czech Republic
}

\begin{abstract}
The paper deals with a methodology proposed for measuring the concentration of air ions in the environment of speleotherapeutic caves, and with the implementation of the AK-UTEE-v2 ionmeter. Speleotherapy, in the context of its general definition, is the medical therapy that utilizes the climate of selected caves to treat patients with health problems such as asthma. These spaces are characterized by the presence of high air humidity and they make extreme demands on the execution of the measuring device, the Gerdien tube (GT in the following) in particular, and on the amplifier electronics. The result is an automated measuring system using a GT with low-volume air flow, enabling long-term measuring of air ion concentration and determination of spectral ion characteristics. Interesting from the instrumentation viewpoint are the GT design, active shielding, and execution of the electrometric amplifier. A specific method for the calculation of spectral ion characteristics and the mode of automatic calibration were proposed and a procedure of automatic measurement in the absence of attendants was set up. The measuring system is designed for studying and long-term monitoring of the concentration of light negative ions in dependence on climatic conditions and on the mobility of ions occurring in the cave.
\end{abstract}

Keywords: Speleotherapy, air ions, Gerdien tube, climatology.

\section{INTRODUCTION}

Measuring the properties of air ions and their concentration is a hot topic currently being solved at several scientific workplaces [1]-[6]. Tammet describes the working principle of measuring devices with a GT (Gerdien tube) in a survey publication [7]. Another publication, [8], [9], focuses on the evaluation of the mobility spectrum of air ions, inclusive of a data analysis with ion size interpretation. The proposed spectrometers are mostly of the stationary type, suitable for meteorological stations designed for measuring in an air-conditioned building [10], [11]. Some interesting spectrometers and GT for meteorological purposes are given in [1], [10]-[14]. From the viewpoint of determining the mobility spectrum of air ions, the measurement using a GT with a segmented internal electrode is more rapid but less accurate.

In a number of medical research projects, reported for example in [15]-[19], it has been proved that light negative ions have a positive effect on human health and their lack results in fatigue, health problems, and reduced performance at work. For example, special ionizers were tested that employ the stimulation of plants placed in a salt solution with high electric voltage [20], and their influence and effect on the tracheas of laboratory (sewer-) rats were evaluated, together with an analysis of the state of their blood. Measuring the concentration of air ions is widely applied in monitoring the degree of air pollution, hygiene checks at workplaces, health therapy - speleotherapy [21]-[23], in the study of electric phenomena in the atmosphere and, topically, in forecasting earthquakes [24], [25] or other weather anomalies. Aplin [26] describes the effects of atmospheric electricity on its surroundings and the manner it is generated in the troposphere. The area of interest extends into astrophysics, with focus on the exploration of atmospheric discharges and ionization on gaseous planets of the solar system [27].

All these applications work with data on the concentration of light air ions, with the mobility spectrum of ions measured with a relevant accuracy and with metrologically properly obtained data. It is therefore indispensable to set the measuring process and the measuring methodology such that analyses and evaluations can be performed on the derived and monitored phenomena.

Currently, a method for measuring the concentration of air ions using a GT is widely used. One of the greatest advantages of this method is the possibility of evaluating the 
mobility spectrum (spectral characteristics) of air ions from the measurements carried out [28]. Other methods such as those given in [28] and [15] lack this possibility.

The measurement of air ions in speleotherapeutic cave conditions is burdened with great uncertainties. These are primarily due to the high relative humidity in the cave (100\%), slow air flow with pronounced ion fluctuation under strong ionization of air by radon. A serious disadvantage of the air ion meters is that in an environment with high relative humidity they do not work or they only measure for a limited, very short period of time. The measuring ambiguity is also greatly affected by the presence of persons and by their motion in the cave during therapy and measurement.

The present work is concerned with a methodology of air ion measurement to be applied in speleotherapeutic caves. These spaces are characterized by the presence of high air humidity and they make extreme demands on the execution of the measuring device, the GT in particular, and on the amplifier electronics. The result is an automated measuring system using a GT with a low-volume air flow, enabling long-term measurements of air ion concentration and determination of spectral ion characteristics. The measuring system is designed for the study of and search for varied concentration of light negative ions in dependence on climatic conditions, and the mobility of ions occurring in the caves.

\section{Methodology OF ION CONCENTRATION MEASUREMENT}

Problems of the methodology of measuring air ions with the aid of a GT require a complex solution including several mutually complementary areas.

To eliminate uncertainties in the measurement of ion concentration it is necessary to design and experimentally verify an appropriate conception of the measuring system with a GT for use in therapeutic cave spaces. These spaces are characterized by the presence of high air humidity and thus they make extreme demands on the execution of the measuring device, in particular the GT and the electronics, inclusive of the amplifier.

The mutual relationship between the concentrations of

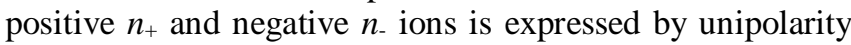
coefficient $P$.

$$
P=\frac{n_{+}}{n_{-}}
$$

\section{SPELEOTHERAPEUTIC CAVES}

In a speleotherapeutic cave, child patients suffering from bronchial asthma are treated. According to medical reports, as many as $10-15 \%$ of children in the Czech Republic (CR) [29] suffer from this disease; thus it is a problem with societal impact. In CR, asthma treatment using speleotherapy is practised in the Eden Zlaté Hory centre in the Jeseníky Mountains, and also in the child sanatorium in Ostrov u Macochy, where the measurement using the proposed methodology was performed. The treatment takes place in the Císařská jeskyně, which was specially adapted for purposes of speleotherapy. It is a cold cave of the karst type.

The environmental theory currently characterizes the healing effects of speleotherapeutic caves by a set of components, factors and processes of the cave endoenvironment and their clinically verifiable interactions with the human body. The confirmed effects that influence the patient's state of health can be characterized by the following parameters [29]:

- constant cave temperature, ranging from $7-8^{\circ} \mathrm{C}$;

- high relative air humidity, attaining $100 \%$ for most of the year;

- high concentration of light negative and positive ions, generated by radionuclides contained in limestone (uranium, thorium and radioactive potassium); The unipolarity coefficient approaches $P=1$, and the related mobility is $k>1,28 \mathrm{~cm}^{2} \cdot \mathrm{V}^{-1} \cdot \mathrm{s}^{-1}$.

- content of calcium and magnesium ions in aerosol;

- modest air flow;

- low dust content, absence of allergens and bacteria.

\section{ELECTRIC FIELD DISTRIBUTION IN GT}

Of the greatest importance for the metrological properties of the method with GT is the distribution of electric field. To assess the behaviour of air ions during their passage through GT, a simulation of electric field distribution inside and outside GT was conducted using the finite element method (FEM) [30]-[32]. The field must not markedly influence electric potential in the space being measured. In the space in front of GT the electrostatic field should draw in ions without the formation of electrostatic lenses. Within the given context, we first of all outline the results for the most advantageous arrangement of the electrostatic field as related to the measurement; this particular option was then chosen for our measuring system. The measuring configuration is illustrated in Fig.1. and Fig.2. When three electrodes (inner, outer, and shielding) are used, there are four possible variants, which differ depending on which electrode is earthed. From the simulation results the variant with the earthed outer electrode was chosen.

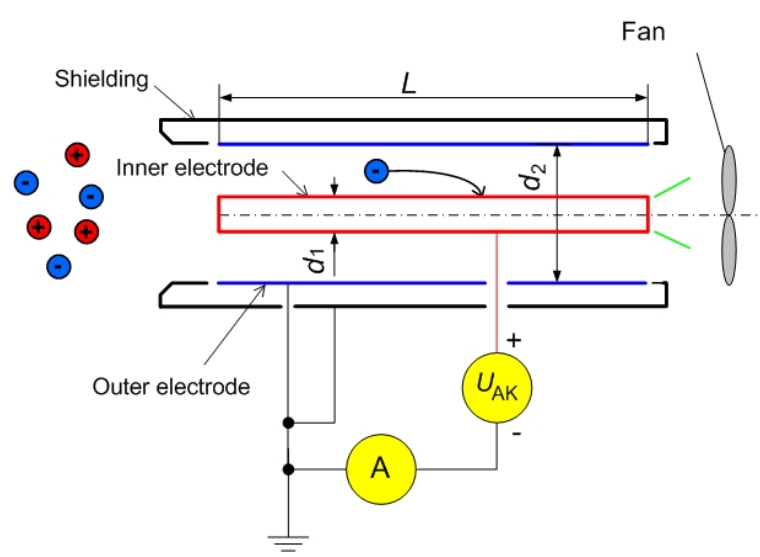

Fig.1. Measuring configuration of the optimal chosen variant for negative ions. 


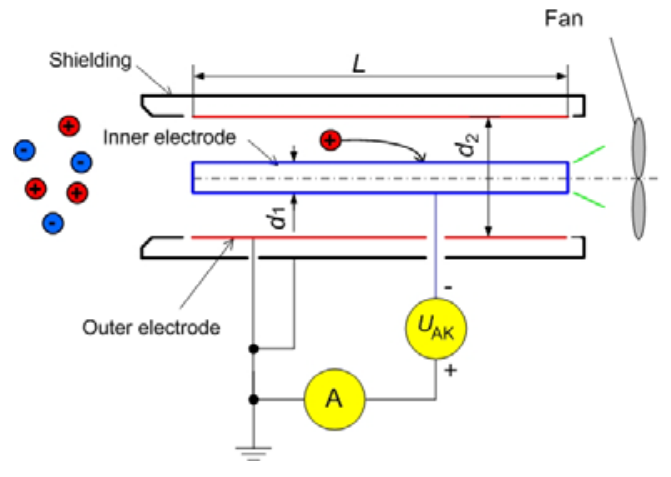

Fig.2. Measuring configuration of the optimal chosen variant for positive ions.

The simulation results in section and near the GT inlet as given in Fig.3. confirm a low effect on the intensity of electric field $E$ in the space being measured, and appropriate suction of air ions without the formation of an electrostatic lens on the input.
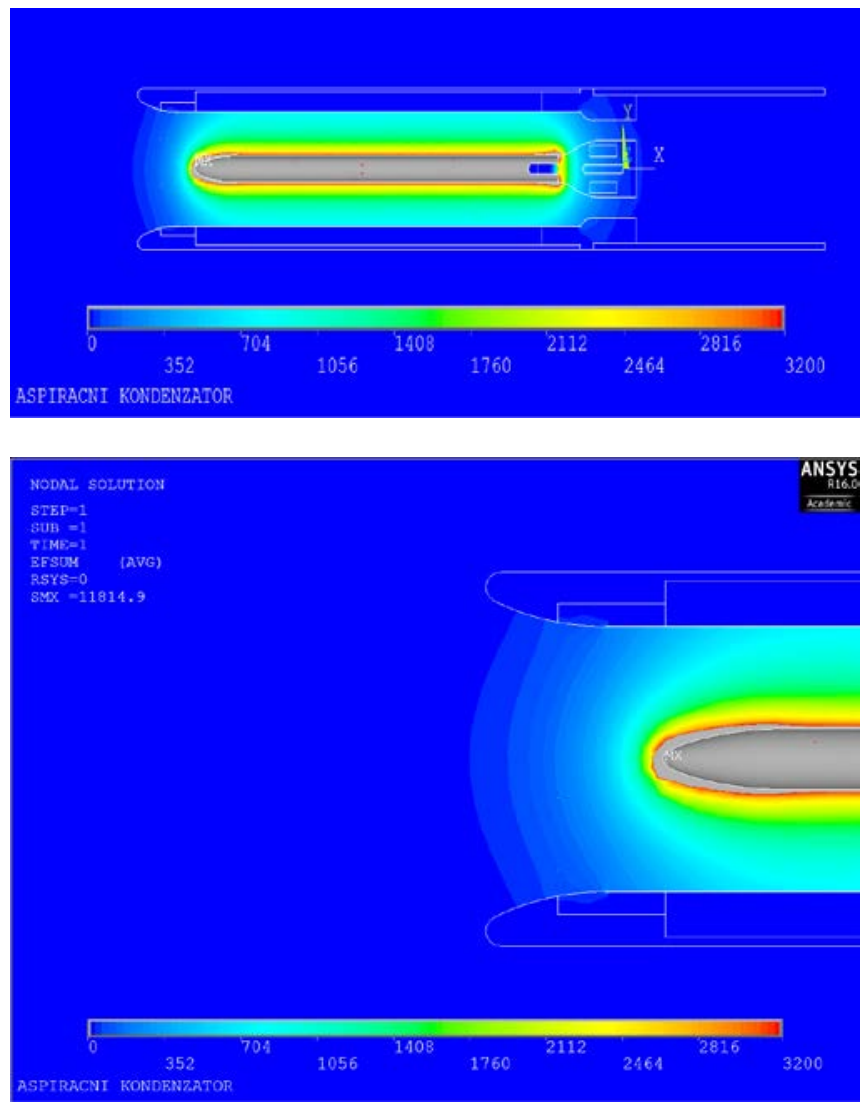

Fig.3. Distribution of intensity $E$ in GT section (up) and on the GT input (down), with the scale limited to $3200 \mathrm{~V} / \mathrm{m}$ (valid for both negative and positive ions). The relevant polarization voltage corresponds to $U_{\mathrm{AK}}=25 \mathrm{~V}$.

The electric field intensity increases in the direction of the inner collecting electrode. There is no deformation of the trajectory of air ions and no drop in the measured concentration of air ions caused by the change in the polarization voltage $U_{\mathrm{AK}}$. Near the inner electrode edges the drop in intensity $E$ is not compensated for by edge effects, and the deviation $\Delta E$ may reach as much as $-15 \%$ from the ideal dependence. At the end of the inner electrode there are divergences in the FEM due to the sharp edge, and the intensity $E$ is assumed to be higher than in other variants of electrode earthing. For $90 \%$ of the space between the inner and the outer electrode the ideal distribution of electric field holds, similar to the cylindrical capacitor. Thus, there is no drop in the measured concentration of air ions that would still be dependent on the magnitude of the voltage $U_{\mathrm{AK}}$. This property can be decisive for the measurement of ion fields in small constrained spaces. The result of the simulation is the proposal of suitable dimensions and distribution of potentials in GT (Table 1.).

In their relevant articles, [3], [14], Aplin and Kolarž connect the inner electrode to the potential of the earth, whereas the polarization voltage is led to the outer electrode. This approach is simpler due to the guarding principle used in the electrometric amplifier; however, as shown by the simulation, the solution can also be considered inconvenient in terms of the distribution of the electromagnetic field. Fig.4. represents the configuration for the measurement of negative ions; in measuring positive ions, positive voltage is led to the outer electrode.

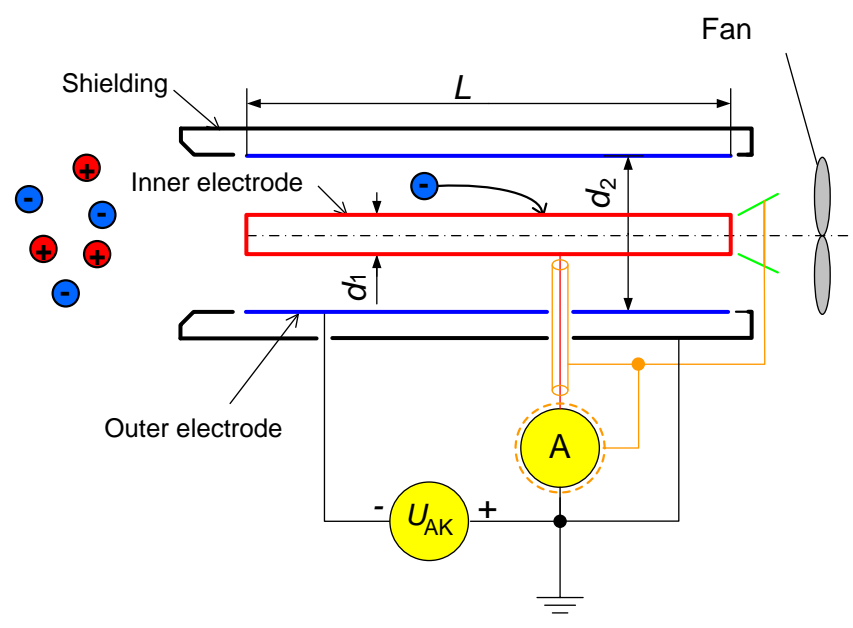

Fig.4. Measuring configuration utilized by Aplin and Kolarž for negative ions.

The distribution of intensity $E$ is represented in Fig.5., which shows that the necessary shielding coat of the GT on the potential of the earth causes an electrostatic lens to form in front of the inner electrode at the inlet of the GT. The lens then prevents a portion of the ions from reaching the collecting electrode, and their concentration measured in this variant is thus lower than that found in the measured space. The detailed distribution of intensity $E$ at the mouth of the GT is shown in Fig.5.

Ions are drawn into the GT by a ventilator. The ventilator motor must be magnetically shielded in order not to influence the ion trajectory in GT. Shielding is provided by a ferrite cylinder surrounding the motor. Commutator motors are a source of considerable interference and are not suitable for the proposed measurement. 

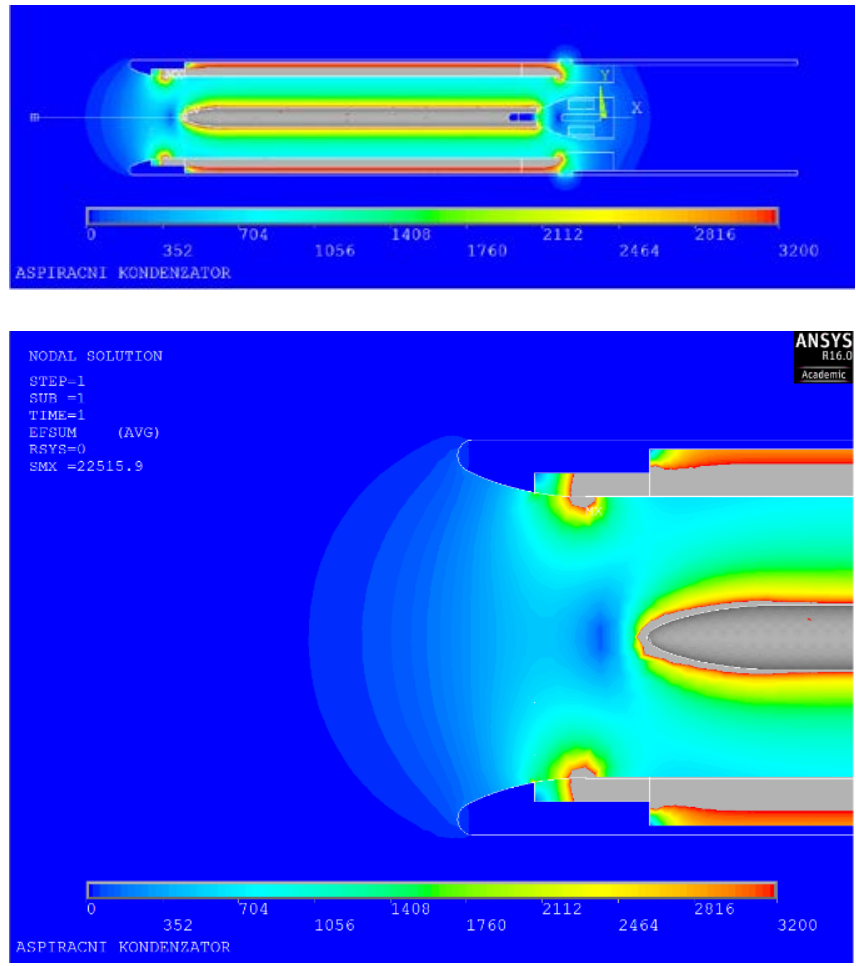

Fig.5. Distribution of intensity $E$ in GT section (up) and on the GT input (down), with the scale limited to $3200 \mathrm{~V} / \mathrm{m}$ (valid for both negative and positive ions). The relevant polarization voltage corresponds to $U_{\mathrm{AK}}=25 \mathrm{~V}$.

Table 1. Properties of AK-UTEE-v2 [33].

\begin{tabular}{|l|c|}
\hline & AK-UTEE \\
\hline Diameter $d_{2}[\mathrm{~mm}]$ & 38 \\
\hline Diameter $d_{1}[\mathrm{~mm}]$ & 12 \\
\hline Inner electrode length $L[\mathrm{~mm}]$ & 160 \\
\hline Flow velocity $v_{\mathrm{x}}\left[\mathrm{m} \cdot \mathrm{s}^{-1}\right]$ & 2.1 \\
\hline Volume flow rate of air $M\left[\mathrm{~cm}^{3} \cdot \mathrm{s}^{-1}\right]$ & 2140 \\
\hline Capacitance $C_{\mathrm{AK}}[\mathrm{pF}]$ & 7.7 \\
\hline Limit mobility $\mathrm{km}\left[\mathrm{cm}^{2} \cdot \mathrm{V}^{-1} \cdot \mathrm{s}^{-1}\right]$ & $\frac{24.5}{U_{\mathrm{AK}}}$ \\
\hline $\begin{array}{l}\text { Voltage } U_{\mathrm{AK}} \text { required for measuring light } \\
\text { ions with the mobility } k>1.7 \mathrm{~cm}^{2} . \mathrm{V}^{-1} . \mathrm{s}^{-1}\end{array}$ & 14.4 \\
\hline
\end{tabular}

In our GT, the relationship between the concentration of air ions $n$ and the measured current $I$ corresponds to

$$
n=2140 \cdot I
$$

where the current $I$ is expressed in $\mathrm{pA}$, and $n$ in $\mathrm{cm}^{3} \cdot \mathrm{s}^{-1}$.

\section{CONCEPTION OF ELECTROMETRIC AMPLIFIER}

Much attention needs to be paid to the measurement of very small currents of the order of $10^{-12}$ to $10^{-15} \mathrm{~A}$. It is necessary to choose an electrometric amplifier design with minimum noise and to increase the insulation resistance of GT via employing a relay for range switching and using active shielding. It is good to characterize the effect of active shielding on the pulse response of a change in the concentration of air ions [34].

In view of the very low currents being measured it is necessary to eliminate the measuring cables and interfering electric and magnetic fields. A special electrometric amplifier is located as close to the GT collecting electrode as possible and is shielded from outer electromagnetic fields [34]. Feedback connection of the operational amplifier with an electrometric feedback resistor was chosen. This connection exhibits lower noise and it also filters the measured current data. The fundamental connection of electrometric amplifier showing the effect of input quiescent current $i_{\mathrm{B}}$ - and input residual voltage $u_{\mathrm{OS}}$ is given in Fig.6. An OPA129 operational amplifier was used in the electrometric amplifier. Table 2. gives the values of equivalent scheme elements for AK-UTEE-v2.
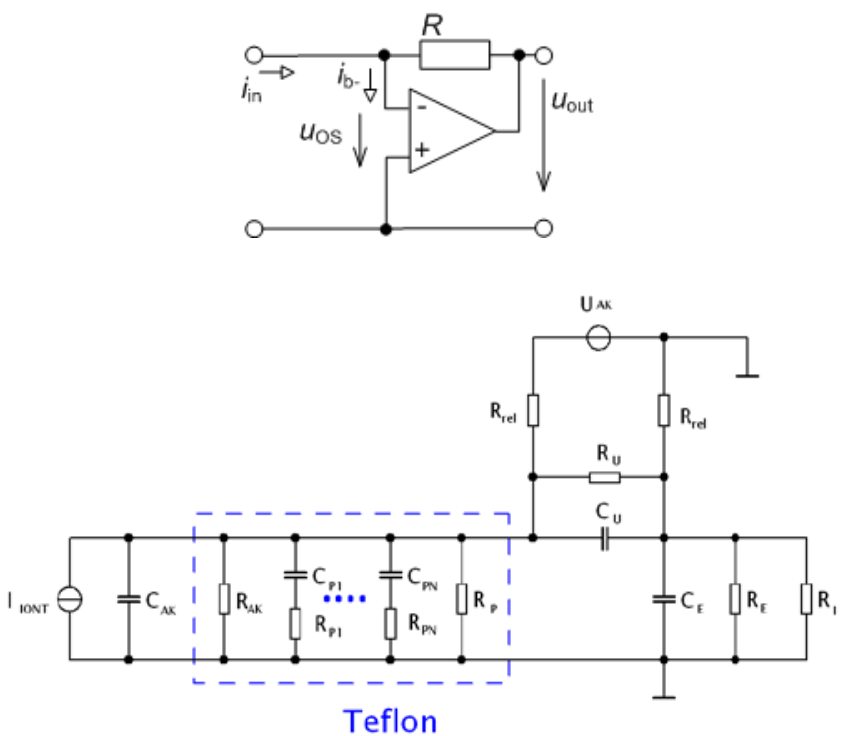

Fig.6. Fundamental connection of electrometric amplifier (top) and equivalent scheme of the AK-UTEE-v2 system (bottom).

Table 2. Properties of AK-UTEE-v2 [33].

\begin{tabular}{|l|l|l|}
\hline \multicolumn{2}{|l|}{ AK-UTEE } & capacitance of GT \\
\hline$C_{\mathrm{AK}}$ & $7.7 \mathrm{pF}$ & $\begin{array}{l}\text { leakage resistance of GT and } \\
\text { Teflon bushing }\end{array}$ \\
\hline$R_{\mathrm{AK}} \| R_{\mathrm{P}}$ & $5000 \mathrm{~T} \Omega$ & $\begin{array}{l}\text { RC element modelling the } \\
\text { Teflon DA }\end{array}$ \\
\hline$C_{\mathrm{P} 1}, R_{\mathrm{P} 1}$ & $0.7 \mathrm{pF}, 40 \mathrm{~T} \Omega$ & $\begin{array}{l}\text { polarization capacitor with } \\
\text { leakage resistance }\end{array}$ \\
\hline$C_{\mathrm{U}}, R_{\mathrm{U}}$ & $1 \mu \mathrm{F}, 100 \mathrm{~T} \Omega$ & $\begin{array}{l}\text { capacitance of the lead to } \\
\text { sensing resistor }\end{array}$ \\
\hline$C_{\mathrm{E}}$ & $3 \mathrm{pF}$ & $\begin{array}{l}\text { leakage resistance of the lead } \\
\text { to sensing resistor }\end{array}$ \\
\hline$R_{\mathrm{E}}$ & $1000 \mathrm{~T} \Omega$ & $\begin{array}{l}\text { leakage resistance of } \\
\text { charging relays }\end{array}$ \\
\hline$R_{\mathrm{REL}}$ & $100 \mathrm{~T} \Omega$ & $\begin{array}{l}\text { input resistance of } \\
\text { electrometric amplifier }\end{array}$ \\
\hline$R_{\mathrm{I}}$ & $10 \mathrm{k} \Omega$ & $\begin{array}{l}\text { source for polarization } \\
\text { capacitor charging }\end{array}$ \\
\hline$U_{\mathrm{AK}}$ & $25 \mathrm{~V}$ & \\
\hline
\end{tabular}


The source of polarization voltage was implemented by a polarization capacitor $C_{U}$ [34]. During the measurement, it is charged at regular intervals to a polarization voltage $U_{\mathrm{AK}}$. While charging, the measurement is interrupted and, using a relay (a special, custom-made relay developed at DTEEE, with a Teflon skeleton and high-quality reed contacts A46), the capacitor $C_{U}$ is switched over to controllable voltage source via both terminals. The purpose of using the capacitor is to obtain minimum leakage currents. The period of a new charging of $C_{\mathrm{U}}$ should be $4000 \mathrm{~s}$ and, if measuring in a cave, up to $50.10^{5} \mathrm{~s}$ [34]. With longer periods of charging the $C_{U}$, significant errors may appear when measuring the saturation characteristics.

\section{ACTIVE SHIELDING}

An important problem when measuring in an environment with high air humidity is the appropriate earthing of GT that will eliminate the effect of electrostatic fields near the measuring device. In simulations using the FEM the effect of earthing can be examined by applying an interference potential to the outer electrode and determining its effect on the results of measuring the concentration of air ions for different configurations.

The selected configuration does not enable us to employ a shield clamp in the electrometric amplifier to facilitate active shielding; we therefore designed a novel, unique solution.

Since with the earthed outer GT electrode the classical active shielding cannot be applied, active shielding with an auxiliary capacitor $C_{\mathrm{AS}}$ was proposed (Fig.7.). At the beginning of the measurement, the $C_{\mathrm{As}}$ capacitor together with the polarization capacitor $C_{\mathrm{E}}$ is charged to the voltage $U_{\mathrm{AK}}$. One of its pins is earthed, the other is connected to the shielding ring of the bushing shielding and the shielding bevelled ring of the inner electrode Teflon holder. After disconnecting the polarization voltage source, the $C_{\mathrm{AS}}$ capacitor is actively shielding the inner electrode.

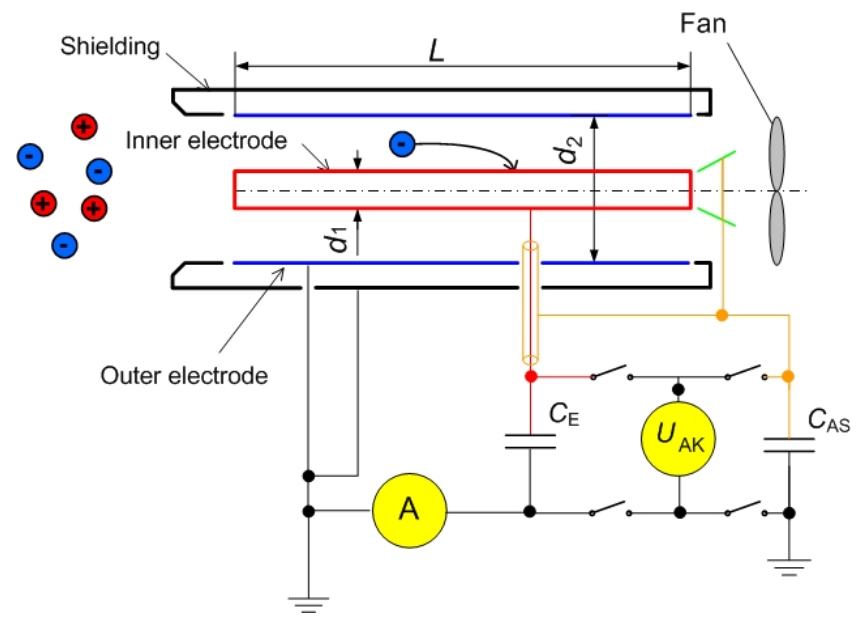

Fig.7. Schematic illustration of active shielding.
The reason for using a further capacitor is that the polarization voltage $U_{\mathrm{AK}}$ can attain a value of up to $60 \mathrm{~V}$ and it is necessary to use a further amplifier with a higher supply voltage. The pins of active shielding cannot be connected directly to the source of polarization voltage because its implementation is unipolar and its polarity is changed via a relay on the output. The $C_{\mathrm{AS}}$ capacitor is discharged by leakage current according to the relation

$$
I_{\text {svod }}=\frac{U_{\mathrm{AK}}}{R_{\mathrm{AK}} \| R_{\mathrm{P}}}
$$

The error in the concentration measured is then caused by the voltage difference between the $C_{\mathrm{E}}$ and $C_{\mathrm{AS}}$, given by their different ways of discharging during the measuring process. Experimental measurements revealed that a period of 30 min was sufficient to recharge the two capacitors to the polarization voltage.

\section{MEASURING PROCEDURE}

A properly chosen measuring procedure will enable eliminating the effect of the electrostatic field of the space being measured, the leakage current of GT, the effect of earthing, and the dynamics of the change in time of the concentration of air ions. The proposed automated measuring system AK-UTEE-v2 (Fig.8.) has an electrometric amplifier located on the GT shielding jacket. The block diagram of the proposed equipment is shown in Fig.9. The electrometric amplifier includes a polarization capacitor, which is periodically charged from a HV source. The electrometric amplifier is zeroed with the GT ventilator off, using a D/A converter. The value measured on the output of electrometric amplifier is digitized by a 16-bit A/D converter and processed in an AVR microcontroller. In automatic measurement the algorithm is controlled by the microcontroller, which in addition to providing the measuring mode also saves the measuring results in a FLASH memory or transfers them into a PC via USB interface in the case of manual measurement. The conception of the meter allows automatic measurement of ion concentration in the absence of attendants and periodic automatic compensation of the electrometric amplifier zero.

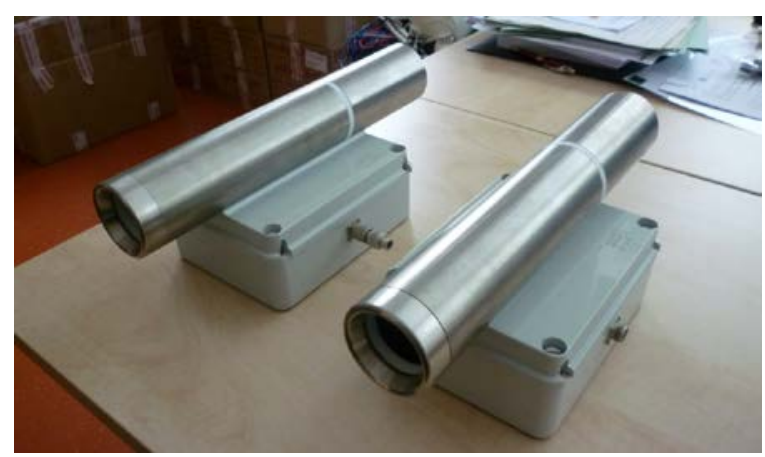

Fig.8. Two AK-UTEE-v2 measuring systems for measuring negative and positive ions. 


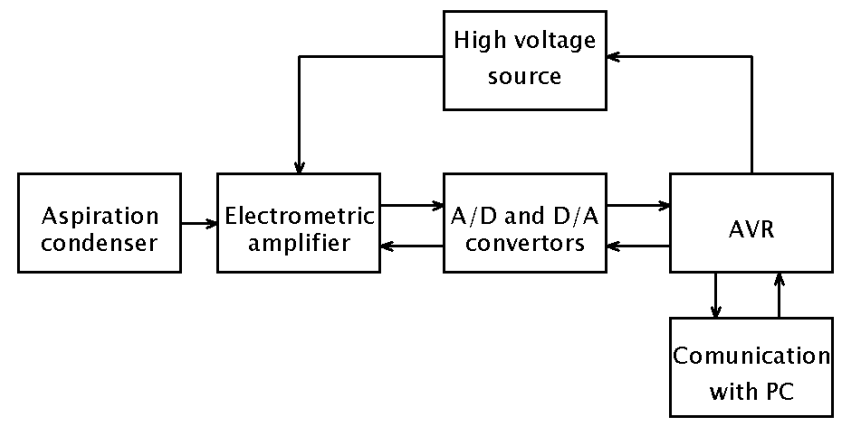

Fig.9. Block diagram of AK-UTEE-v2.

\section{CALCULATION OF MOBILITY SPECTRUM OF AIR IONS}

The processing of the values measured and the calculation of the spectral characteristics of air ions must suppress noise, and the proposed algorithm should be little sensitive to the time fluctuation of the concentration of air ions.

The saturation characteristic is the dependence of the measured electric current flowing through GT on the polarization voltage $U_{\mathrm{AK}}$ (schematic in Fig.1.). In [28] and [34] Israël derived a relation for the number of ions with greater mobility than the limit mobility $k_{\mathrm{m}}$ for a given polarization voltage $U_{\mathrm{AK}}$.

$$
\int_{k_{\mathrm{m}}}^{\infty} n(k) \mathrm{d} k=Z-U_{\mathrm{AK}} \frac{\mathrm{d} Z}{\mathrm{~d} U_{\mathrm{AK}}}
$$

where $n$ is the number of ions, $k$ is the ion mobility, and $Z$ is an auxiliary variable according to (4).

$$
Z=\frac{I}{\mathrm{q} \cdot M}
$$

The characteristic $Z$ is graphically illustrated in Fig.8. To establish the amount of ions in the mobility interval $\left(k_{\mathrm{m} 1}\right.$ to $k_{\mathrm{m} 2}$ ) the first derivatives are obtained for two polarization voltages $U_{\mathrm{GT}}$, and the point of intersection with the axis y is found, Fig.10.

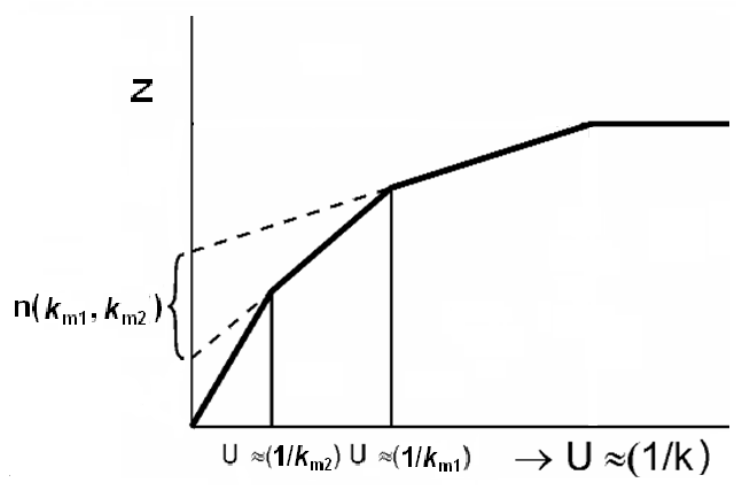

Fig.10. Example of establishing the mobility spectrum of air ions (adjusted according to [28]).
The result of the calculation of ions in the interval $k_{\mathrm{m} 1}<k_{\mathrm{m} 2}$ is given by the relation

$$
n\left(k_{\mathrm{m} 1}, k_{\mathrm{m} 2}\right)=\int_{k_{\mathrm{m} 1}}^{\infty} n(k) \mathrm{d} k-\int_{k_{\mathrm{m} 2}}^{\infty} n(k) \mathrm{d} k
$$

A new method was therefore proposed for the calculation of the spectral characteristic. The ion spectrum was calculated via fitting the saturation characteristic with the sum of several functions $G$ (7), using the least squares method. The function $G$ expresses the number of measured ions with different mobility values and it is

$$
G= \begin{cases}\frac{C_{\mathrm{AK}} \cdot U_{\mathrm{AK}} \cdot k}{\varepsilon_{0}} & \text { for } k<k_{\mathrm{m}} \\ M & \text { for } k \geq k_{\mathrm{m}}\end{cases}
$$

For a continuous spectrum, an infinite number of such functions would be necessary. According to experimental results, it is in most cases sufficient to consider a spectrum of two to three principal mobility values of ions. The saturation characteristic should be a monotonously rising function [36]. The calculation of the mobility spectrum of air ions from relation (6) is highly sensitive to fluctuation and noise [37], [38]. One point of the saturation characteristic must therefore be obtained from the average of 100 measured values of light ion concentration. Still, it is affected by large measuring uncertainties. The proposed method does not perform the first derivative of the saturation characteristic measured and does not emphasize fluctuation in the saturation characteristic waveform measured. This method markedly reduces the effect of undesirable noise and instability of the concentration of light negative ions in a space.

For the numerical method of least squares the function lsqcurvefit was made use of in the MATLAB environment. The saturation characteristic was measured at regular time intervals of $2 \mathrm{~s}$. To eliminate the effect of ventilator start, 125 values of current were measured, with the first 25 measured values not taken into consideration. Measuring one point of the saturation characteristic took $250 \mathrm{~s}$. Subsequently, the ventilator was turned off, followed by measuring 25 values with the ventilator off. Measuring the whole of the saturation characteristic takes 2.5 hours. During this period there is no marked change in the cave temperature $\left(8.1^{\circ} \mathrm{C}\right)$ and relative humidity (it usually reached $100 \% \mathrm{RH})$. The saturation characteristic can therefore be used for a representative description of the mobility of air ions in a cave.

The resultant conversion of saturation characteristic (Fig.11.a)) for AK-UTEE-v2 is given in Fig.11.b). An advantage of this procedure is that in spite of the significant type A uncertainty for $U_{\mathrm{AK}}=14 \mathrm{~V}$, the function was fitted correctly. The obtained results correspond to the common mobility spectra shown in several studies, such as [7]; specific are high mobility ions $13.7 \mathrm{~cm}^{2} \cdot \mathrm{V}^{-1} \cdot \mathrm{s}^{-1}$. 


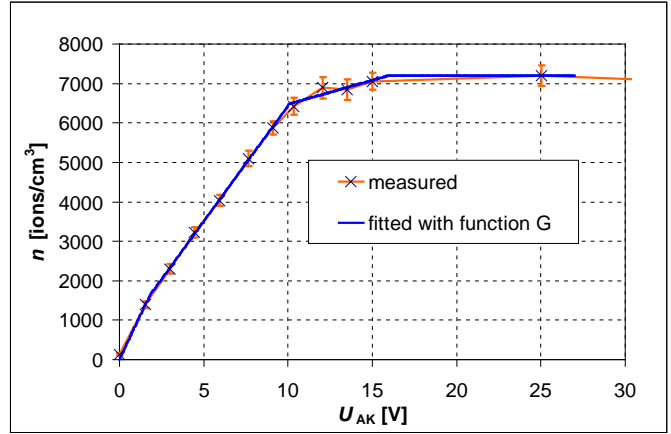

a)

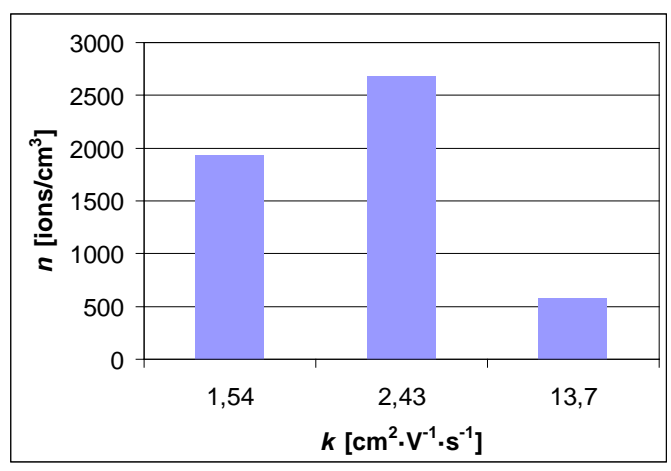

b)

Fig.11. a) measured and approximated saturation characteristics, b) obtained mobility spectrum.

\section{RESULTS AND DISCUSSION}

To test the correct function of AK-UTEE-v2, a comparative measurement was conducted with the device AK MGK-01 (Kathrein) as a reference apparatus, which is used in the National Institute of Public Health in Prague. AK MGK-01 contains a high-quality electrometric modulation amplifier AD310K. It is employed to verify the concentration of air ions generated by ionizers, and to assess the ion atmosphere at workplaces. Since there was no shielded Faraday chamber available at NIPH, the comparative measurement was conducted in a room designed for ionizer testing. The reference ionizer was placed on a desk covered with a conductive and earthed surface. Both measuring devices were placed on desks with identical surfaces (Fig.12.).

Within the initial step, carried out in Prague on Nov. 2, 2011, we compared the performance obtained at two different distances from the ionizer; the established correction coefficient corresponded to $\mathrm{K}=1.47$. In the subsequent measurement, we used the direct output of the ionmeter, and the related voltage was measured with an Agilent 34401A multimeter.

The measurement on Feb. 21, 2012, was conducted twice, for distances of 1, 1.5 and $2 \mathrm{~m}$ from a BIV-07 ionizer; the measurement was not affected by attendants' motion. The relationship between the concentrations measured with the UTEE and the MGK-01 ionmeters is outlined in Fig.12. In addition, due to the longer time constant of the filtering integration circuit in AK MGK-01, the fluctuations in the air ion concentration caused by the instability of the reference ionizer are shifted. Turning off the AK-UTEE-v2 ventilator did not change the AK MGK-01 data. A similar check was performed by disconnecting the supply of AK MGK-01, the AK-UTEE-v2 did not change either. The two measuring systems did not affect each other.
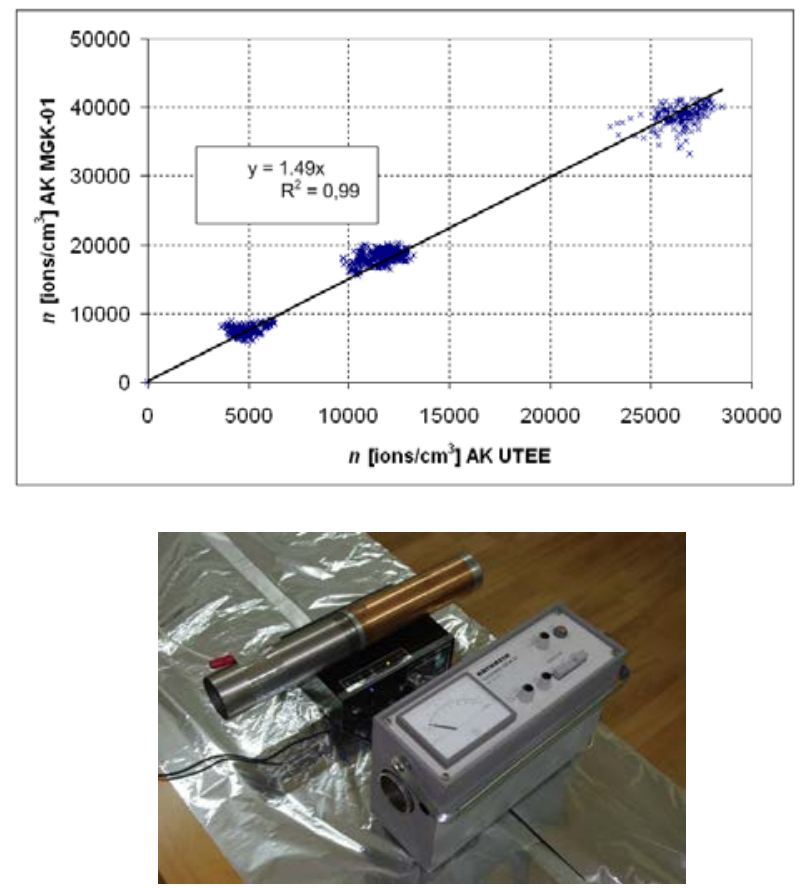

Fig.12. Comparison of measured waveforms from AK-UTEE-v2 and AK MGK-01 (at time $600 \mathrm{~s}$ the AK-UTEE-v2 ventilator was turned off) at a distance of $1.5 \mathrm{~m}$ from BIV-07 ionizer (top), position of both devices during measurement (down).

Table 3. Comparison of AK-UTEE-v2 and AK-MGK-01, Feb. 21, 2012.

\begin{tabular}{|c|c|c|}
\hline $\begin{array}{l}\text { Distance from } \\
\text { ionizer }\end{array}$ & AK-UTEE-v2 & AK-MGK-01 \\
\hline$[\mathrm{m}]$ & {$\left[\right.$ ions $\left./ \mathrm{cm}^{3}\right]$} & {$\left[\right.$ ions $\left./ \mathrm{cm}^{3}\right]$} \\
\hline 1.0 & $26700 \pm 900$ & $38800 \pm 1400$ \\
\hline 1.5 & $14400 \pm 600$ & $18000 \pm 1000$ \\
\hline 2.0 & $5350 \pm 610$ & $8140 \pm 1000$ \\
\hline
\end{tabular}

Table 3. gives the measured air ion concentrations and their select standard deviations for AK-UTEE-v2 and AKMGK-01. The air ion concentration was obtained from the average of measured values at times of 100 to $500 \mathrm{~s}$. The chosen measuring interval was $1 \mathrm{~s}$. Fig.12. shows a comparison of 2,000 measured values in both ionmeters. From the regression curve, we established the correction coefficient of $\mathrm{K}=1.49$.

The described new AK-UTEE-v2 system will enable longterm measurement in caves. An example of 7-day measurement in the area of Moravian Karst - Císařská jeskyně, the Nagel Dome, employed for speleotherapy (temperature $8.1^{\circ} \mathrm{C}$, absolute pressure $980 \mathrm{hPa}$, relative humidity $\mathrm{h}=100 \%$ ) is given in Fig.13. During the 
therapeutic stay a group of 30 children is divided into two halves, with one half sleeping in the 'couch sector', the other playing in the Nagel Dome (usually referred to as playroom). The children come to the cave at 1 p.m. and leave at 4 p.m., swapping their roles in the middle of the stay.

The changes in time of the insulation resistance $R_{\mathrm{i}}$ can be interpreted as $l / f$ noise affecting the measured concentration of light ions. The effect of $R_{\mathrm{i}}$ can be suppressed via automatic compensation of the GT zero, which is done periodically every half-hour. During this period the polarization capacitor does not get markedly discharged and the value of the GT leakage current does not change either. Due to the application of this principle, the measurement can proceed for up to one week.
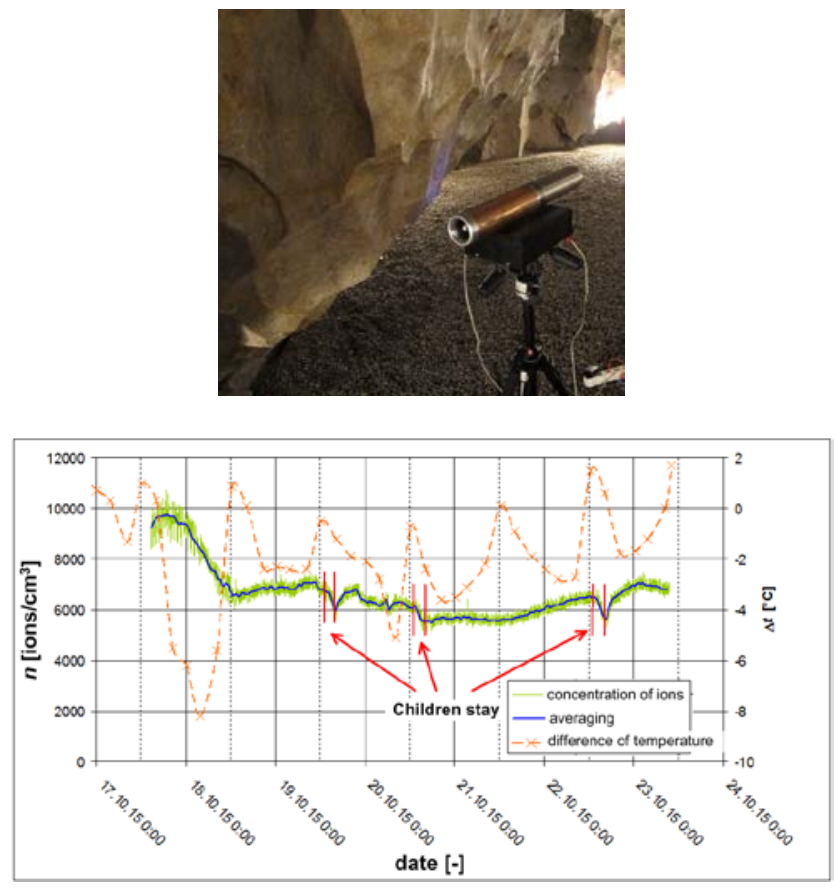

Fig.13. Measuring in cave (top) and the time dependence of concentration of light negative ions in the course of a week, together with the respective temperature difference between cave interior and cave surroundings (down).

The automatic measurement used when measuring the concentration of air ions in a cave is an absolute measurement. In differential measurement, an absolute identity of the two GTs is assumed and unknown distribution of electrostatic field in the space being measured affects the measuring accuracy. In the absolute measurement of the concentration of air ions using one GT the measurement is affected, apart from the required concentration of light air ions, also by: a) electrostatic field in the space measured, b) fluctuations in the GT leakage current caused by dirty insulant surface or phenomena related to dielectric absorption, c) GT contamination by radioactive substances, d) electrometric amplifier noise, in particular its low-frequency component $l / f$. To eliminate the above effects, a new methodology of absolute measurement was proposed for the AK-UTEE-v2 system. Even with the ventilator off, GT measures the residual current which is the result of the electrostatic field of the ionizer when ions move by diffusion from the ionizer tip to the collecting electrode. GT is therefore zeroed with the ion generator on.

The resultant saturation characteristic is obtained by subtracting from each measured value the value of the current when the ventilator is off. Furthermore, one measurement is performed with zero polarization voltage $U_{\mathrm{AK}}$ in order to eliminate the effect of electrostatic field in the space measured. It is assumed that the electrostatic field distribution does not markedly change in time. After removing the $\mathrm{l} / \mathrm{f}$ noise, it is necessary to periodically zero the electrometric amplifier. This will suppress the change in the GT leakage current caused by impurities and potential aqueous film, and also the effect of temperature on the input quiescent current of the operational amplifier.

\section{CONCLUSION}

The above-described measuring system AK-UTEE-v2 enables long-term measuring of the concentration of air ions in the environment of speleotherapeutic caves. It operates on the familiar principle of measuring the current flowing through a GT, whose electric field draws in air ions. For long-term measuring of the concentration of ions in humid environment (more than 7 days) a specific measuring procedure is proposed consisting of regular measurements of leakage currents, and their application in the automatic calibration mode. The procedure used in automatic measurement enables long-term measuring and elimination of measuring errors caused by the presence of attendants. Interesting from the instrumentation viewpoint are the lowvolume air flow, GT design, unique active shielding, and appropriate connection of electrometer amplifier.

Since obtaining a defined concentration of air ions is very problematic, experimental comparative measurement was performed on the AK-UTEE-v2 and AK MGK-01 (Kathrein) systems, the latter being used by the National Institute of Public Health in Prague. Compared with the AK MGK-01 system, the AK-UTEE-v2 system measures a lower value of ion concentration with a lower standard deviation, with the average value of correction coefficient $K_{\text {ion }}=1.49$.

Unlike other applicable systems, [3], [4], [5], [14], the AK-UTEE-v2 was designed to facilitate more advantageous distribution of the electrostatic field in the mouth of the condenser; such an arrangement enables us to measure the saturation characteristics in a more accurate manner and to exploit these in computing the air ion mobility spectrum. In this context, for example, a relevant paper by Kolarž [40] shows the typical deformation of saturation characteristics, most probably caused by an inappropriate measuring configuration (Fig.4.). A very beneficial property of the GT consists in the low volumetric flow rate, whose effect on the sensitive environment of the cave is negligible.

The measuring system exhibits good qualities suitable for the study and long-term monitoring of the concentration of light negative ions in dependence on climatic conditions, and of the mobility of ions occurring in speleotherapeutic caves. 


\section{ACKNOWLEDGMENT}

This work was supported by a grant from the Ministry of Education, Youth and Sports of the Czech Republic (LO1212), the research described in this paper was supported by Czech Science Foundation under grant No. 1309086S.

\section{REFERENCES}

[1] Hörrak, U. (2001). Air ion mobility spectrum at a rural area. PhD thesis, University of Tartu, Estonia.

[2] Aplin, K.L., Harrison, R.G. (2001). A self-calibrating programable mobility spectrometer for atmospheric ion measurements. Review of Scientific Instruments, 72 (8), 3467-3469.

[3] Aplin, K.L., Harrison, R.G. (2000). A computercontrolled Gerdien atmospheric ion counter. Review of Scientific Instruments, 71 (8), 3037-3041.

[4] Harrison, R.G., Aplin, K.L. (2000). A multimode electrometer for atmospheric ion measurements. Review of Scientific Instruments, 71 (12), 4683-4685.

[5] Harrison, R.G., Aplin, K.L. (2007). Water vapour changes and atmospheric cluster ions. Atmospheric Research, 85 (2), 199-208.

[6] Hirsikko, A., et. al. (2011). Atmospheric ions and nucleation: A review of observations. Atmospheric Chemistry and Physics, 11, 767-798.

[7] Tammet, H., Kulmala, M. (2005). Simulation tool for atmospheric aerosol nucleation bursts. Journal of Aerosol Science, 36 (2), 173-196.

[8] Harrison, R.G., Tammet, H. (2008). Ions in the terrestrial atmosphere and other solar system atmospheres. Space Science Reviews, 137 (1-4), $107-$ 118.

[9] Grabarzyk, Z. (2001). Frequency characteristic of an aspiration integrating small ion counter with a shielded collector. Journal of Electrostatics, 51-52, 284-289.

[10] Tammet, H. (2006). Continuous scanning of the mobility and size distribution of charged clusters and nanometer particles in atmospheric air and the Balanced Scanning Mobility Analyzer BSMA. Atmospheric Research, 82 (3), 523-535.

[11] Mirme, A., Tamm, E., Mordas, G., Vana, M., Uin, A.J., Mirme, S., Bernotas, T., Laakso, L., Hirsikko, A., Kulmala, M. (2007). A widerange multi-channel Air Ion Spectrometer. Boreal Environment Research, 12, 247-264.

[12] Tammet, H., Mirme, A., Tamm, E. (2002). Electrical aerosol spectrometer of Tartu University. Atmospheric Research, 62 (3-4), 315-324.

[13] Biskos, G., Reavell, K., Collings, N. (2005). Description and theoretical analysis of a differential mobility spectrometer. Aerosol Science and Technology, 39, 527-541.

[14] Kolarž, P., Marinković, B.P., Filipović, D.M. (2005). Zeroing and testing units developed for Gerdien atmospheric ion detectors. Review of Scientific Instruments, 76 (4), 046107.
[15] Charry, J.M., Kavet, R. (1987). Air Ions: Physical and Biological Aspects. CRC Press.

[16] Sirota, V., Safronova, V.G., Amelina, A.G., Maltseva, V.N., Avkhacheva, N.V., Sofin, A.D., Yanin, V.A., Mubarakshina, E.K., Romanova, L.K., Novoselov, V.I. (2008). The effect of negative air ions on the respiratory organs and blood. Biophysics, 53 (5), 457462.

[17] Sirota, T.V., Novoselov, V.I., Safronova, V.G., Yanin, V.A., Tsvetkov, V.D., Amelina, S.E., Lushnikova, A.L., Maltseva, V.N., Tikhonov, V.P., Kondrashova, M.N. (2006). The effect of inhaled air ions generated by technical ionizers and a bioionizer on rat trachea mucosa and the phagocytic activity of blood cells. IEEE Transactions on Plasma Science, 34 (4), 13511358.

[18] Tikhonov, V.P., Temnov, A.A., Kushnir, V.A., Sirota, T.V., Litvinova, E.G., Zakharchenko, M.V., Kondrashova, M.N. (2004). Complex therapeutical effect of ionized air: Stimulation of the immune system and decrease in excessive serotonin. $\mathrm{H} 2 \mathrm{O} 2$ as a link between the two counterparts. IEEE Transactions on Plasma Science, 32 (4), 1661-1667.

[19] Kondrashova, M.N., Grigigorreko, E.V., Tikhonov, A.N., Sirota, T.V., Temnov, A.V., Stavrovskaya, I.G., Kosyakova, N.I., Lange, N.V., Tikonov, V.P. (2000). The primary physico-chemical mechanism for the beneficial biological/medical effects of negative air ions. IEEE Transactions on Plasma Science, 28 (1), 230-237.

[20] Tikhonov, V.P., Tsvetkov, V.D., Litvinova, E.G., Sirota, T.V., Kondrashova, M.N. (2004). Generation of negative air ions by plants upon pulsed stimulation applied to soil. Journal of Plant Physiology, 51 (3), 414-419.

[21] Szabó, Z., Bartušek, K. (2009). Air ions concentration influence on bacterial colony count in the dwelling spaces. In PIERS Proceedings, Moscow, Russia, August 18-21, 2009, 1053-1055.

[22] Kolarž, P.M., Filipović, D.M., Marinković, B.P. (2009). Daily variations of indoor air-ion and radon concentrations. Applied Radiation and Isotopes, 67 (11), 2062-2067.

[23] Kolarž, P., Gaisberger, M., Madl, P., Hofmann, W., Ritter, M., Hartl, A. (2011). Characterization of ions at Alpine waterfalls. Atmospheric Chemistry \& Physics Discussions, 11 (9), 3687-3697.

[24] Freund, F.T., Kulahci, I.G., Cyr, G., Ling, J., Winnick, M., Tregloan-Reed, J., Freund, M.M. (2009). Air ionization at rock surfaces and pre-earthquake signals. Journal of Atmospheric and Solar-Terrestrial Physics, 71 (17-18), 1824-1834.

[25] Freund, F. (2011) Pre-earthquake signals: Underlying physical processes. Journal of Asian Earth Sciences, 41 (4-5), 383-400.

[26] Aplin, K.L. (2008). Composition and measurement of charged atmospheric clusters. In Planetary Atmospheric Electricity. Springer, Vol. 30, 213-224. 
[27] Leblanc, F., Aplin, K.L., Yair, Y., Harrison, G., Lebreton, J.P., Blanc, M. (Eds.) (2008). Planetary Atmospheric Electricity. Springer.

[28] Israël, H. (1971). Atmospheric Electricity. Vol. I. Jerusalem: IPST.

[29] Jirka, Z. (2001). Speleoterapie: principy a zkušenosti. 1. vyd. Olomouc: Univerzita Palackého. (in Czech)

[30] Bartušek, K., Fiala, P., Jirků, T., Kroutilová, E. (2007). Experiments of accuracy air ion field measurement. PIERS Online, 3 (8), 1330-1333.

[31] Steinbauer, M., Fiala, P., Bartušek, K., Szabó, Z. (2008). Experiments with accuracy of air ion field measurement. In PIERS Proceedings, Hangzhou, China, March 24-28, 2008, 1062-1066.

[32] Roubal, Z., Křepelka, P. (2013). Estimation of the air ion mobility spectrum by means of a Gerdien Tube with a segmented inner electrod. In PIERS Proceedings, Stockholm, Sweden, August 12-15, 2013, 767-771.

[33] Roubal, Z., Szabó, Z., Steinbauer, M. (2014). Uncertainty determination in measurements using a Gerdien Tube. In PIERS Proceedings, Guangzhou, China, August 25-28, 2014, 1902-1906.

[34] Israël, H., Schulz, L. (1933). The mobility-spectrum of atmospheric ions-principles of measurements and results. Journal of Geophysical Research, 38 (4), 285300.

[35] Roubal, Z., Steinbauer, M. (2010). Design of electrometric amplifier for aspiration condenser measurement. In PIERS Proceedings, Xi'an, China, March 22-26, 2010, 1430-1434.

[36] Bartušek, K., Dokoupil, Z. (2003). Automatic device for ion fields measurement. Measurement Science Review, 3 (3), 75-78.

[37] Roubal, Z., Steinbauer, M., Szabó, Z. (2010). Modeling of saturation characteristic of an aspiration condenser. PIERS Online, 6 (1), 26-30.

[38] Roubal, Z., Bartušek, K., Szabó, Z., Drexler, P. (2011). Measurement of concentration and mobility spectrum of air ions in the natural environment. In PIERS Proceedings, Marrakesh, Morocco, March 2023, 2011, 648-652.

[39] Bartušek, K., Burrival, Z., Darina, H. (1999). Methodology of measurement of air ions in moist environment for speleotheraphy. In Measurement '99: 2nd International Conference on Measurement. Bratislava, Slovak Republic: Institute of Measurement Science, Slovak Academy of Sciences, 262-265.

[40] Kolarž, P.M., Filipović, D.M. (2003). A new design of Gerdian type of small air-ion detector. In 5th General International Conference of Balkan Physical Union (BPU-5), August 25-29, 2003, Vrnajcka Banja, Serbia and Montenegro, 411. 